\title{
Comparação de duas técnicas de isolamento do Mycobacterium avium subsp. paratuberculosis em amostras de fezes de ovinos com suspeita clínica de paratuberculose ${ }^{1}$
}

\author{
Ana Cláudia Coelho ${ }^{2,3^{\star}}$, Maria de Lurdes Pinto 2,3 , Adosinda Maria Coelho ${ }^{4} \mathrm{e}$ \\ Jorge Rodrigues ${ }^{2,3}$
}

\begin{abstract}
Coelho A.C., Pinto M.L., Coelho A.M. \& Rodrigues J. 2009. [Comparison of two techniques of isolation of Mycobacterium avium subsp. paratuberculosis in faecal samples of ovine with clinical suspicion of paratuberculosis.] Comparação de duas técnicas de isolamento de Mycobacterium avium subsp. paratuberculosis em amostras de fezes de ovinos com suspeita clínica de paratuberculose. Pesquisa Veterinária Brasileira 29(5):415-420. Departamento de Ciências Veterinárias, Universidade de Trás-os-Montes e Alto Douro, Quinta de Prados, 5001-801 Vila Real, Portugal. E-mail: accoelho@utad.pt

Paratuberculosis is a chronic enteric disease of ruminants caused by Mycobacterium avium subsp. paratuberculosis. Culture of bacteria from faeces and tissues samples constitutes one of the most effective methods of confirming the diagnosis of paratuberculosis and the only method available to obtain strains of mycobacteria. However, this method is less sensitive and requires months of incubation before colony growth occurs. In this study, culture method was used on sheep faeces to diagnose paratuberculosis in animals with compatible signs of the disease. A comparison of two culture media used to isolation was also investigated. Culture was positive in $2.0 \%$ of faecal samples. Isolation was obtained using Löwenstein Jensen ${ }^{\circledR}$ with mycobactin $^{\circledR} \mathrm{J}$, and the Middlebrook ${ }^{\circledR}$ $7 \mathrm{H} 11$ with OADC ${ }^{\circledR}$. The Löwenstein Jensen ${ }^{\circledR}$ with mycobactin ${ }^{\circledR} \mathrm{J}$ was that provided highest amount of isolations. The percentages of isolation in each culture media were $2.0 \%(6 / 300)$ to Löwenstein Jensen ${ }^{\circledR}$ with micobactina J, and 1.0\% (3/300) to Middlebrook ${ }^{\circledR} 7 \mathrm{H} 11 /$ OADC. The three positive samples in Middlebrook ${ }^{\circledR} 7 \mathrm{H} 11 / \mathrm{OADC}$ were also positive in Löwenstein Jensen $^{\circledR}$ with micobactina J. In the Middlebrook ${ }^{\circledR} 7 \mathrm{H} 11 / \mathrm{OADC}$ alone there was no sample growth. The results of this study suggest that culture media of Löwenstein-Jensen ${ }^{\circledR}$ with micobactina ${ }^{\circledR} \mathrm{J}$ is more effective for the isolation of sheep strains in Portugal.
\end{abstract}

INDEX TERMS: Paratuberculosis, ovine, feaces, culture, diagnosis.

RESUMO.- A paratuberculose é uma enterite crônica granulomatosa causada por Mycobacterium avium subsp. paratuberculosis que afeta principalmente os ruminantes. A cultura de bactérias a partir de amostras de fezes e

\footnotetext{
${ }^{1}$ Recebido em 3 de abril de 2007.

Aceito para publicação em 10 de janeiro de 2009.

2 Departamento de Ciências Veterinárias, Universidade de Trás-osMontes e Alto Douro, Apartado 1013, 5001-801 Vila Real Codex. *Autor para correspondência: accoelho@utad.pt

${ }^{3}$ CECAV Portugal.

${ }^{4}$ Direção Geral de Veterinária, Divisão de Intervenção Veterinária de Vila Real, Núcleo do Corgo, Lugar de Codessais, 5000-421 Vila Real, Portugal.
}

tecidos constitui um dos métodos mais eficazes de diagnóstico, sendo ainda o único método disponível para obtenção de isolamentos e estirpes de micobactérias. Contudo, este método apresenta baixa sensibilidade e requer meses de incubação antes do crescimento de colônias. Neste estudo, utilizou-se a cultura fecal como método de diagnóstico em ovinos de diferentes raças portuguesas, com sinais compatíveis com a doença. Fez-se ainda a comparação entre os meios de cultura Löwenstein Jensen ${ }^{\circledR}$ com micobactina $^{\circledR} \mathrm{J}$ e o de Middlebrook ${ }^{\circledR} 7 \mathrm{H} 11$ com $O A D C^{\circledR}$, utilizados no isolamento da bactéria. As percentagens de isolamento em cada um os meios foram de 2,0\% (6/300) para Löwenstein Jensen ${ }^{\circledR}$ com micobac- 
tina J e 1,0\% (3/300) para Middlebrook ${ }^{\circledR} 7 \mathrm{H} 11 / \mathrm{OADC}$. As três amostras positivas no meio de Middlebrook ${ }^{\circledR} 7 \mathrm{H} 11 /$ OADC também foram positivas no meio de Löwenstein Jensen ${ }^{\circledR}$ com micobactina J e nenhuma foi somente positiva no meio de Middlebrook ${ }^{\circledR} 7 \mathrm{H} 11 / \mathrm{OADC}$. Os resultados deste estudo sugerem que o meio de LöwensteinJensen ${ }^{\circledR}$ com micobactina ${ }^{\circledR} \mathrm{J}$ é mais efetivo para a obtenção de estirpes ovinas em Portugal.

TERMOS DE INDEXAÇÃO: Paratuberculose, ovinos, fezes, cultura, diagnóstico.

\section{INTRODUÇÃO}

A paratuberculose, ou doença de Johne, é uma enterite crônica granulomatosa causada por Mycobacterium avium subsp. paratuberculosis (Map) que afeta principalmente os ruminantes. Esta entidade nosológica tem um longo período de incubação, sendo caracterizada por um quadro de emagrecimento progressivo e fatal, acompanhado frequentemente de diarréia (Chiodini et al. 1984). A importância da paratuberculose nos ruminantes domésticos tem sido apresentada em diversos estudos, na medida em que é uma doença que causa perdas econômicas relevantes em todo o mundo (Körmendy et al. 1989, Losinger 2006). O isolamento de Map, a partir de amostras de fezes e de tecidos animais, é a prova considerada de referência. Desde o primeiro isolamento in vitro têm ocorrido importantes avanços no diagnóstico da paratuberculose mediante a utilização desta técnica (Juste et al. 1988, Carrigan \& Seaman 1990, Collins et al. 1990, 1993b, Shulaw et al. 1993, Ristow et al. 2006).

As estirpes ovinas são particularmente difíceis de isolar por cultura, mas apesar disso, esta técnica continua a ser considerada como a de referência para o diagnóstico (Juste et al. 1988, Collins et al. 1990, Pérez et al. 1997).

Mycobacterium avium subsp. paratuberculosis é capaz de crescer na maioria dos meios utilizados para o isolamento de micobactérias, desde que, nos mais comuns, se acrescente micobactina. Os meios de cultura mais utilizados, habitualmente, são aqueles à base de ovo, como o de Herrold (HEYM) (Kim 1989), ou o de Löwenstein -JensenÒ (Adúriz 1993, Garrido 2002). Mas também se usam outros à base de soro, como o de Dubos (Saxegaard 1985), ou mais sintéticos, como as diferentes variantes do meio de Middlebrook ${ }^{\circledR}$ (Adúriz et al. 1995). As colônias em Löwenstein-Jensen ${ }^{\circledR}$ são difíceis de visualizar, necessitando de 40 semanas para o crescimento (Stehman \& Shulaw 1996).

Os meios à base de soro e sintéticos requerem a eliminação por lavagem do descontaminante, quando se utilizam soluções detergentes, as quais são neutralizadas diretamente por fosfolípidos presentes na gema de ovo dos meios que incluem esta composição (Adúriz et al. 1995). A concentração das micobactérias, depois da descontaminação, pode ocorrer por sedimentação (Adúriz 1993), ou por centrifugação. Esta última parece favorecer ligeiramente a velocidade de crescimento da micobactéria e, a sensibilidade de cultura (Kalis et al. 1999), mas, por outro lado, também aumenta o número de culturas desperdiçadas por contaminações (Kim 1989). A adição de antibióticos e antifúngicos à amostra, após as fases de descontaminação e concentração, diminui significativamente este problema (Stabel 1997).

Pretendeu-se com este trabalho comparar duas técnicas de isolamento de Mycobacterium avium susbsp. paratuberculosis em material fecal de ovinos com suspeita clínica de paratuberculose.

\section{MATERIAL E MÉTODOS}

Colheram-se amostras de fezes de 900 animais provenientes de 150 explorações que apresentavam sinais clínicos compatíveis com paratuberculose (emagrecimento, diarréia, edema submandibular, alopecia). As amostras de fezes foram colhidas diretamente do reto, com auxílio de luva, sendo estas mantidas refrigeradas a $4^{\circ} \mathrm{C}$, até serem congeladas a $-20^{\circ} \mathrm{C}$. Em cada propriedade foram colhidas seis amostras de fezes. Foi feito um "pool" de fezes constituído pelas amostras provenientes de cinco animais com sinais compatíveis da doença. As fezes do sexto animal, aquele que apresentava os sinais clínicos mais característicos de paratuberculose ou se encontrava em fase mais avançada de emagrecimento, foram inoculadas de forma individual. Neste caso passaram então a existir duas amostras fecais a ser inoculadas para cada propriedade: uma proveniente do "pool" e uma outra amostra individual pertencente ao animal em piores condições, totalizando 300 amostras. O processamento bacteriológico das diferentes amostras incluiu o método de cultura em que se empregaram os meios de Löwenstein-Jensen ${ }^{\circledR}$ adicionado de micobactina ${ }^{\circledR} \mathrm{J}$ e o meio de Middlebrook $7 \mathrm{H} 11^{\circledR}$ enriquecido com OADC ${ }^{\circledR}$. Todas as amostras foram inoculadas em dois tubos contendo LöwensteinJensen ${ }^{\circledR}$ adicionado de micobactina ${ }^{\circledR} \mathrm{J}$ e dois tubos de Middlebrook $7 \mathrm{H} 11^{\circledR}$ enriquecido com OADC ${ }^{\circledR}$. Como agentes seletivos, adicionaram-se penicilina sódica e cloranfenicol e, como antifúngico, a anfotericina $\mathrm{B}$. As colônias suspeitas foram subcultivadas em Middlebrook $7 \mathrm{H} 9^{\circledR}$ para posterior identificação. Os processos de elaboração dos meios de cultura foram efetuados de acordo com as instruções dos fabricantes.

Para a cultura empregaram-se os métodos descritos por Juste et al. (1991) e Adúriz et al. (1995). Após a descongelação à temperatura ambiente, as amostras foram introduzidas em bolsas de plástico esterilizadas para digestor (Seward ${ }^{\circledR}$ Stomacher 400 ), nas quais se pesou aproximadamente $2 \mathrm{~g}$ de fezes das amostras individuais. Nas amostras de "pool" fecal foi feito um reajuste na quantidade da amostra introduzida: $5 \mathrm{~g}$ para o "pool", constituído por fezes provenientes dos cinco animais com sinais clínicos compatíveis de paratuberculose da mesma propriedade. Seguidamente, homogeneizaram-se as amostras individuais em $35 \mathrm{~mL}$ de uma solução descontaminante de cloreto de hexadecil piridínio (HCP) a 0,75\%, mediante o auxílio do digestor. No caso do "pool" fecal, fez-se um reajuste, sendo adicionado $88 \mathrm{~mL}$ de solução descontaminante. Após a sedimentação das partículas mais grosseiras durante 15-20 minutos pipetaram-se $3 \mathrm{~mL}$ da interfase. Após este procedimento, a pipeta permaneceu na mesma bolsa, em posição vertical durante 18 horas para a descontaminação da amostra. Após este período, procedeu-se à inoculação de, aproximadamente, $0,2 \mathrm{~mL}$ (4 gotas) em dois tubos de meio de cultura de LöwensteinJensen ${ }^{\circledR}$ com micobactina J. Para evitar a maior concentração 
de micobactérias na parte inferior da pipeta e que o primeiro tubo inoculado tivesse maior quantidade de micobactérias, a inoculação foi realizada em duas fases. Na primeira, inoculouse uma gota em cada um dos tubos, e na segunda fase, colocaram-se três gotas seguidas em cada tubo, mas em ordem inversa, isto é, começando pelo tubo inoculado por último na primeira fase. Todo o procedimento foi efetuado em câmara de fluxo laminar para evitar a contaminação dos meios. Em cada lote incluíram-se dois tubos sem inocular, para descartar a contaminação na fase de produção dos meios, assim como dois tubos inoculados com a estirpe ovina ATCC19698, como controle positivo.

Foram também inoculados tubos contendo o meio de Middlebrook $7 \mathrm{H}_{11}{ }^{\circledR}$ adicionado de OADC ${ }^{\circledR}$. O meio de Middlebrook $7 \mathrm{H} 11^{\circledR}$ carece de ovo na sua composição, pelo que é necessária a eliminação, por lavagem da solução de HCP, do inóculo antes de proceder a semeadura. Após a descontaminação da amostra durante 18 horas, colheram-se $10 \mathrm{~mL}$ da suspensão e transferiram-se para um tubo de plástico esterilizado e hermético. Neste tubo procedeu-se à centrifugação a $5.750 \mathrm{~g}$ durante 20 minutos. Posteriormente, decantouse o sobrenadante e o sedimento foi suspendido em $3 \mathrm{~mL}$ de água destilada esterilizada, após o qual se efetuou a semeadura de acordo com o protocolo descrito anteriormente.

A confirmação do isolamento de Mycobacterium avium subsp. paratuberculosis baseou-se no tempo de incubação, dependência de micobactina $\mathrm{J}$, na morfologia das colônias e na confirmação das estirpes isoladas por análise de PCR e PCRREA.

Após o crescimento das culturas em meio sólido, efetuouse uma subcultura em $10 \mathrm{~mL}$ de meio líquido Middlebrook $7 \mathrm{H} 9^{\circledR}$. Após o crescimento, as bactérias foram recolhidas por centrifugação e suspendidas em $3 \mathrm{~mL}$ de uma solução a $50 \%$ de glicerol $\left(50 \%\right.$ glicerol $+50 \%$ Middlebrook $\left.7 \mathrm{Hg}^{\circledR}\right)$, sendo posteriormente armazenadas a $-80^{\circ} \mathrm{C}$ até a análise de PCR e PCR-REA.

Ao invés de se considerarem positivos o crescimento de colônias compatíveis com Map, só foram considerados válidos os isolamentos nos quais foi possível amplificar um fragmento de $389 \mathrm{pb}$ correspondente à sequência IS900 específica de Mycobacterium avium subsp. paratuberculosis.

\section{Análise dos dados}

Os cálculos foram executados com recurso ao programa SPSS $10.0^{\circledR}$ (SPSS Inc., Chicago III, USA, 2000) para Windows. Para comparar a eficácia dos meios, usou-se o coeficiente "Kappa" (K) de Choen que mediu a concordância proporcional não aleatória (Altman, 1991), sobre os resultados obtidos nos diferentes métodos laboratoriais. Um valor de $\mathrm{K}$ de 0,5 indica um moderado nível de concordância entre as técnicas. Um valor de $\mathrm{K}>0,80$ representa excelente concordância proporcional não aleatória. Para este cálculo foi utilizado o programa WinEpiscope $2.0^{\circledR}$.

\section{RESULTADOS}

A análise por PCR-REA identificou as estirpes isoladas em cultura como pertencentes ao tipo $S$ (ovino). A cultura foi positiva em seis $(2,0 \%)$ das 300 amostras de fezes analisadas: três eram amostras do tipo "pool" e três, amostras individuais.

A percentagem de isolamento nos meios de cultura de fezes foi de $2,0 \%$ para o Löwenstein-Jensen ${ }^{\circledR}$ com mico- bactina $J$ após, uma média de 8 meses de incubação e $1,0 \%$ para o meio de Middlebrook ${ }^{\circledR} 7 \mathrm{H} 11 / \mathrm{OADC}$, após se descartarem as amostras inutilizadas ao final de dois meses. O cálculo da percentagem de culturas positivas e negativas fez-se com base nas culturas válidas, enquanto que as culturas inutilizadas (contaminadas ou desidratadas) foram calculadas com base no total de amostras (Quadro 1). Nenhuma amostra foi considerada inutilizada no meio de Löwenstein-Jensen ${ }^{\circledR}$ com micobactina J, na medida em que, durante o tempo em que se realizou este estudo, aquando da detecção desta condição, os meios foram novamente inoculados, não tendo ocorrido, em nenhum caso, dupla inutilização. Contudo, 10 amostras foram inutilizadas, por contaminação fúngica ou bacteriana, no meio de Middlebrook ${ }^{\circledR} 7 \mathrm{H} 11 /$ OADC.

As percentagens de isolamento em cada um dos meios, uma vez descartadas as amostras inutilizadas por contaminação ou desidratação, foram de 2,0\% para Löwenstein Jensen ${ }^{\circledR}$ com micobactina $\mathrm{J}$ e 1,0\% para Middlebrook $^{\circledR} 7 \mathrm{H} 11 / \mathrm{OADC}$ (Quadro 2). As três amostras positivas no meio de Middlebrook ${ }^{\circledR} 7 \mathrm{H} 11 / \mathrm{OADC}$ foram também positivas no meio de Löwenstein Jensen ${ }^{\circledR}$ com micobactina J.

Observa-se que, das seis culturas positivas, só três foram positivas no meio de Löwenstein-Jensen ${ }^{\circledR}$ com micobactina J, três haviam ocorrido em ambos os meios e nenhuma foi, somente positiva, no meio de Middlebrook ${ }^{\circledR}$ 7H11/OADC. A concordância observada foi de 50,0\% e o valor de kappa 0,0 (Quadro 2).

Quanto à relação entre o número de tubos de cada meio inoculados (2 por amostra) e o número dos mesmos

Quadro 1. Resultados obtidos das amostras de fezes nos dois meios de cultura, expressos em número e percentagem (LJ+MJ: meio de Löwenstein-Jensen ${ }^{\circledR}$ adicionado de micobactina ${ }^{\circledR} \mathrm{J}$; 7H11+OADC: meio de Middlebrook ${ }^{\circledR}$ 7H11 adicionado de ácido oléico, albumina, dextrose e catalase - OADC ${ }^{\circledR}$ )

\begin{tabular}{lccc}
\hline & LJ+MJ & 7H11+OADC & Total \\
\hline Positivos & $6(2,0 \%)$ & $3(1,0 \%)$ & $6(2,0 \%)$ \\
Negativos & $294(98,0 \%)$ & $287(99,0 \%)$ & $294(98,0 \%)$ \\
Válidos & $300(100 \%)$ & $290(96,7 \%)$ & $300(100 \%)$ \\
Inutilizados & $0(0 \%)$ & $10(3,3 \%)$ & $0(0 \%)$ \\
Total & 300 & 300 & 300
\end{tabular}

Quadro 2. Resultado da comparação dos meios de cultura nos quais se obtiveram isolamentos

\begin{tabular}{lc}
\hline & LJ+MJ/7H11+OADC a \\
\hline Positivo/positivo & $3(1,0 \%)$ \\
Positivo/negativo & $3(1,0 \%)$ \\
Negativo/positivo & $0(0 \%)$ \\
Negativo/negativo & $294(98,0 \%)$ \\
Total & 300 \\
Concordância & $50,0 \%$ \\
Kappa & 0,0
\end{tabular}

a $\mathrm{LJ}+\mathrm{MJ}=$ meio de Löwenstein-Jensen ${ }^{\circledR}$ adicionado de micobactina ${ }^{\circledR} \mathrm{J}$; $7 \mathrm{H} 11+\mathrm{OADC}=$ meio de Middlebrook ${ }^{\circledR} 7 \mathrm{H} 11$ adicionado de OADC ${ }^{\circledR}$ 


\section{Quadro 3. Relação entre o número de tubos inoculados e o número de tubos com crescimento positivo nos dois meios de cultura}

\begin{tabular}{cc}
$\begin{array}{c}\text { Löwenstein Jensen }^{\circledR} \\
+ \text { micobactina }\end{array}{ }^{\circledR} \mathrm{J}$ & Middlebrook $^{\circledR}$ \\
& $7 \mathrm{H} 11+$ OADC $^{\circledR}$ \\
\hline
\end{tabular}

$10 / 600(1,7 \%)$

$3 / 600(0,5 \%)$

com crescimento positivo, observou-se um rendimento de 1,7\% para Löwenstein-Jensen ${ }^{\circledR}$ com micobactina J e 0,5\% para Middlebrook ${ }^{\circledR}$ 7H11 (Quadro 3).

\section{DISCUSSÃO}

O diagnóstico da paratuberculose em ovinos é particularmente difícil. Não existe um teste de referência que permita a detecção de todos os animais infectados. Tradicionalmente, no diagnóstico da infecção ovina, recorre-se a testes serológicos combinados com o exame clínico e o exame bacteriológico das fezes (Hilbink et al. 1994, Clarke et al. 1996, Collins 1996, Pavlík et al. 2000). A cultura foi positiva em $2,0 \%$ das 300 amostras cultivadas. Os resultados da técnica PCR-REA sobre as estirpes isoladas, que foram identificadas como pertencentes ao tipo $S$ (ovino), estão de acordo com os observados por outros autores (Whittington et al. 1998, Marsh et al. 1999, Sevilla et al. 2005).

Quanto à técnica de diagnóstico utilizada, os fracos resultados observados quanto às taxas de isolamento em cultura fecal, são semelhantes aos referenciados em idênticos estudos em ovinos (Juste et al. 1988, Carrigan \& Seaman 1990, Collins et al. 1990, 1993b, Shulaw et al. 1993), mas inferiores a outros documentados (Adúriz et al. 1995, Garrido 2002). Este fato pode ser explicado pela dificuldade do crescimento das estirpes ovinas (Juste et al. 1988, Collins et al. 1990, 1993a,b) ou pela carga bacteriana da amostra abaixo do limite de detecção (Thoen \& Baum 1988). Por outro lado, a excreção da micobactéria de forma intermitente ou abaixo do limiar de detecção podem ser responsáveis pelas baixas prevalências de isolamento em cultura (Thoen \& Baum 1988, Garrido 2002). A aplicação do protocolo de descontaminação ou ainda, o fato de metade das amostras serem do tipo "pool", podem justificar os fracos resultados em cultura. Está provado que, durante a descontaminação, o número de microrganismos viáveis é, consideravelmente reduzido, assim como, na posterior remoção de alíquotas para a inoculação dos meios (Reddacliff et al. 2003). Mokresh et al. (1989) encontraram uma redução de cerca de $2 \log _{10} \mathrm{mi}-$ crorganismos após a exposição dos mesmos a $0,75 \%$ de HCP, durante 18 horas. Este descontaminante foi usado no protocolo de cultura, de ambos os meios, utilizados neste estudo. Também Redacliff et al. (2003) provaram que havia perda do número de estirpes ovinas na ordem de 2,7 $7 \log _{10}$ por amostra de fezes e de $3,1 \log _{10}$ para amostras de tecidos preparados pelo método de sedimentação, de 2,2 $2 \log _{10}$ para amostras de tecidos sujeitas a centrifugação. Usando estes valores e assumindo uma amostra de $2 \mathrm{~g}$ utilizada, o limite de detecção seria de $2,4 \log _{10}$ $\left(2,5 \times 10^{2}\right)$ micobactérias por grama de fezes, na cultura fecal por sedimentação; $2,8 \log _{10}\left(6,3 \times 10^{2}\right)$ para a técnica de sedimentação em tecidos e $1,9 \log ^{10}\left(7,9 \times 10^{1}\right)$ para a centrifugação de tecidos. Como tal, quando pequenas concentrações de microrganismos estão presentes nas amostras, os falsos negativos tornam-se frequentes (Reddacliff et al. 2003).

O outro fator que pode ter influenciado o resultado da cultura fecal, está, provavelmente, relacionado com o fato de metade das amostras terem sido do tipo "pool", o que poderia reduzir a sensibilidade da técnica. Neste estudo empregou-se a amostra de "pool" fecal constituída por fezes de 5 animais da mesma exploração com suspeita clínica de paratuberculose. A cultura por "pool" fecal tem surgido recentemente como uma alternativa válida e a baixo custo para a detecção de Map (Whittington et al. 2000, Scott et al. 2002, Wells et al. 2002, Kalis et al. 2004, Gumber \& Whittington 2007). Contudo, os casos paucibacilares podem ficar comprometidos, e a cultura fecal poderá sofrer um efeito de diluição causado pela amálgama de fezes (Whittington et al. 2000, Wells et al. 2002, Gumber \& Whittington 2007). Como Map não se encontra distribuído de forma homogênea nas fezes, os resultados da cultura podem variar, especialmente nos fracos excretores (Visser 1999). Outro fator que limita a taxa de sucesso em "pool" é a eficácia da mistura das amostras a incluir. É necessário garantir a completa homogeneização e, este objetivo, por vezes, é difícil de se alcançar (Whittington et al. 2000).

Comparando os diferentes meios de cultura utilizados, as taxas de isolamento foram superiores no meio de Löwenstein-Jensen ${ }^{\circledR}$ com micobactina ${ }^{\circledR} \mathrm{J}$ quando comparadas com as obtidas com o meio de Middlebrook ${ }^{\circledR} 7 \mathrm{H} 11$ enriquecido com OADC ${ }^{\circledR}$, independentemente do tipo de amostras inoculadas. A melhor "performance" do LöwensteinJensen ${ }^{\circledR}$ com micobactina ${ }^{\circledR} \mathrm{J}$ não está de acordo com os resultados obtidos por Adúriz e seus colaboradores (1995) que observaram uma eficácia semelhante para ambos os meios. Este fato poderá estar relacionado com uma maior dependência de micobactina $J$ das estirpes ovinas isoladas em Portugal. Embora outros fatores possam ter contribuído para a discrepância dos resultados, não parece, contudo, que se prendam à qualidade do meio de Middlebrook $^{\circledR} 7 \mathrm{H} 11$ ou do suplemento OADC ${ }^{\circledR}$ utilizado que ao apresentarem algum problema específico tenham reduzido a eficácia, visto que a estirpe de referência e alguns isolados cresceram. Quanto à contaminação dos meios, os resultados também foram discrepantes em relação aos apresentados por Adúriz e colaboradores (1995), visto que, no presente estudo, se observou maior número de culturas inutilizadas por formas bacterianas e fúngicas no meio de Middlebrook ${ }^{\circledR} 7 \mathrm{H} 11$ enriquecido com OADC ${ }^{\circledR}$. Convém, contudo, salientar que todas as amostras inutilizadas no meio de Löwenstein-Jensen ${ }^{\circledR}$ com micobacti$\mathrm{na}^{\circledR} \mathrm{J}$ foram, novamente inoculadas no mesmo meio, situação que se repetiu quatro vezes. Estes resultados podem ser explicados com base nas precauções tomadas 
para evitar qualquer tipo de contaminação, durante a confecção do meio de Löwenstein-Jensen ${ }^{\circledR}$ com micobacti$n \mathrm{n}^{\circledR} \mathrm{J}$ como a correta imersão dos ovos em etanol, na medida em que, a bibliografia consultada, refere que a presença de ovo fresco na composição do meio favorece a contaminação (Adúriz 1993, Adúriz et al. 1995).

Os resultados deste estudo sugerem que o meio de Löwenstein-Jensen ${ }^{\circledR}$ com micobactina ${ }^{\circledR} \mathrm{J}$ é mais efetivo para a obtenção de estirpes ovinas em Portugal.

Agradecimentos.- Aos técnicos do laboratório de Microbiologia do Departamento de Ciências Veterinárias da Universidade de Trás-osMontes e Alto Douro, assim como, aos técnicos do Departamento de Sanidade Animal do Instituto Vasco de Investigación y Desarrollo Agrário- NEIKER, Bizcaia, Espanha, em especial ao Doutor Ramón Juste e Iker Sevilla.

\section{REFERÊNCIAS}

Adúriz J.J. 1993. Epidemiologia, diagnostico y control de la paratuberculosis ovina en la Comunidad Autonoma del Pais Vasco. Tese de Doutoramento, Universidade de Zaragoza. 283p.

Adúriz J.J., Juste R.A. \& Cortabarria N. 1995. Lack of mycobactin dependence of mycobacteria isolated on Middlebrook $7 \mathrm{H} 11$ from clinical cases of ovine paratuberculosis. Vet. Microbiol. 45:211-217.

Carrigan M. \& Seaman J. 1990. The pathology of Johne's disease in sheep. Aust. Vet. J. 67:47-50.

Chiodini R.J., Van Kruiningen H.J. \& Merkal R.S. 1984. Ruminant paratuberculosis (Johne's disease): The current status and future prospects. Cornell Vet. 74:218-262.

Clarke C.J., Patterson P., Armstrong K.E. \& Low J.C. 1996. Comparison of the absorbed ELISA and agar gel immunodiffusion test with clinicopathological findings in ovine clinical paratuberculosis. Vet. Rec. 139:618-621.

Collins D.M., Gabric D.M. \& Lisle G.W. 1990. Identification of two groups of Mycobacterium paratuberculosis strains by restriction endonuclease analysis and DNA hybridization. J. Clin. Microbiol. 28:15911596.

Collins D.M., Hilbink F., West D.M., Hosie B.D., Cooke M.M. \& de Lisle G.W. 1993a. Investigation of Mycobacterium paratuberculosis in sheep by faecal culture, DNA characterization and the polymerase chain raction. Vet. Rec. 133:599-600.

Collins D.M., Stephens D.M. \& Lisle G.W. 1993b. Comparison of polymerase chain reaction tests and faecal culture for detecting Mycobacterium paratuberculosis in bovine faeces. Vet. Microbiol. 36:289-299.

Collins M.T. 1996. Diagnosis of paratuberculosis. Vet. Clin. North Am. Food Anim. Pract. 12:357-371.

Garrido J.M. 2002. Puesta a punto de técnicas PCR en heces y de ELISA para el diagnóstico de la paratuberculosis. Estudio de prevalencia en ganado bovino. Tese de Doutoramento, Universidade de Zaragoza. 256p.

Gumber S. \& Whittington R.J. 2007. Comparison of BACTEC 460 and MGIT 960 systems for the culture of Mycobacterium avium subsp. paratuberculosis $\mathrm{S}$ strain and observations on the effect of inclusion of ampicillin in culture media to reduce contamination. Vet. Microbiol. 119:42-52.

Hilbink F., West D.M., Lisle G.W., Kittelberger R., Hosie B.D., Hutton J., Cooke M.M. \& Penrose M. 1994. Comparison of a complement fixation test, a gel diffusion test and two absorbed and unabsorbed ELISAs for the diagnosis of paratuberculosis in sheep. Vet. Microbiol. 41:107116.

Juste R.A., Marco J.C., Sáez de Ocáriz C. \& Adúriz J.J. 1991. Com- parison of different media for the isolation of small ruminant strains of Mycobacterium paratuberculosis. Vet. Microbiol. 28:385-390.

Juste R.A., Sáez de Ocáriz C. \& Marco J.C. 1988. Diagnosis of clinical paratuberculosis in sheep: a comparison of pathological, bacteriological and serological methods In: Proceedings of the second International Colloquium on paratuberculosis. Maisons-Alfort. p.220-226.

Kalis C.H., Barkema H.W. \& Hesselink J.W. 1999. Certification of dairy herds as free of paratuberculosis using culture of strategically pooled faecal samples, p.55-59. In: Manning E.J.B. \& Collins M.T. (Eds), Proc. VI Int. Coll. PTBC, Melbourne, Australia.

Kalis C.H., Collins M.T., Barkema H.W. \& Hesselink J.W. 2004. Certification of herds as free of Mycobacterium paratuberculosis infection: Actual pooled faecal results versus certification model predictions. Prev. Vet. Med. 65:189-204.

Kim Y.G., Bech-Nielsen S., Gordon J.C., Slemons R.D. \& Spangler E. 1989. Comparison of two methods for isolation of Mycobacterium paratuberculosis from bovine fecal samples. Am. J. Vet. Res. 50:11101113.

Körmendy B., Kopál T., Bálint T., Szilágyi M. \& Béki L. 1989. Economic losses caused by paratuberculosis in a dairy herd: case report. Acta Vet. Hung. 37:45-53.

Losinger W.C. 2006. Economic impacts of reduced milk production associated with epidemiological risk factors for Johne's disease on dairy operations in the USA. J. Dairy Res. 73:33-43.

Marsh I.B., Whittington R. \& Cousins D. 1999. PCR-restriction endonuclease analysis for identification and strain typing of Mycobacterium avium subsp. paratuberculosis and Mycobacterium avium subsp. avium based on polymorphism in IS1311. Mol. Cell Probes 13:115126.

Mokresh A.H., Czuprynski C.J. \& Butler D.G. 1989. A rabbit model for study of Mycobacterium paratuberculosis infection. Infect. Immun. 57:3798-3807.

Pavlík I., Matlova L., Bartl J., Svastova P., Dvorska L. \& Whitlock R. 2000. Parallel faecal and organ Mycobacterium avium subsp. paratuberculosis culture of different productivity types of cattle. Vet. Microbiol. 77:309-324.

Pérez V., Tellechea J., Badiola J.J., Gutiérrez M. \& García-Marín J.F. 1997. Relation between serologic response and pathologic findings in sheep with naturally acquired paratuberculosis. Am. J. Vet. Res. 58:799-803.

Reddacliff L.A., Vadali A. \& Whittington R.J. 2003. The effect of decontamination protocols on the numbers of sheep strain Mycobacterium avium subsp. paratuberculosis isolated from tissues and faeces. Vet. Microbiol. 95:271-282.

Ristow P., Silva M.G., Fonseca L.S. \& Lilenbaum W. 2006. Evaluation of Mycobacterium avium subsp. paratuberculosis faecal culture protocols and media. Pesq. Vet. Bras. 26:1-4.

Saxegaard F. 1985. Isolation of Mycobacterium paratuberculosis from intestinal mucosa and mesenteric lymph nodes of goats by use of selective Dubos medium. J. Clin. Microbiol. 22:312-313.

Scott J.W., Whitlock R.H., Lindeman C.J. \& Fyock T. 2002. Evaluation of bacteriologic culture of pooled fecal samples for detection of Mycobacterium paratuberculosis. Am. J. Vet. Res. 63:1207-1211.

Sevilla I., Singh S.V., Garrido J.M., Adúriz G., Rodríguez S., Geijo M.V., Whittington R.J., Saunders V., Whitlock R.H. \& Juste R.A. 2005. Molecular typing of Mycobacterium avium subspecies paratuberculosis strains from different hosts and regions. Rev. Sci. Tech. Off. Int. Epiz. 24:1061-1066.

Shulaw W.P., Bech-Nielsen S., Rings D.M., Getzy D.M. \& Woodruff T.S. 1993. Serodiagnosis of paratuberculosis in sheep by use of agar gel immunodiffusion. Am. J. Vet. Res. 54:13-19.

Stabel J.R. 1997. An improved method for cultivation of Mycobacterium paratuberculosis from bovine fecal samples and comparison to three other methods. J. Vet. Diagn. Invest. 9:375-380. 
Stehman S.M. \& Shulaw W.P. 1996. Paratuberculosis (Johne's disease) in sheep and goats: Recommendations for diagnosis and control. United States Animal Health Association Commitee on Sheep and Goats.

Thoen C.O. \& Baum K.H. 1988. Current knowledge on paratuberculosis. J. Am. Vet. Med. Assoc. 192:1609-1611.

Visser I. 1999. Reproducibility of a faecal culture method for Mycobacterium avium subsp. Paratuberculosis, p.512. In: Proc. 6th Int. Colloquium on Paratuberculosis. Melbourne.

Wells S.J., Whitlock R.H., Lindeman C.J. \& Fyock T. 2002. Evaluation of bacteriologic culture of pooled fecal samples for detection of Mycobacterium paratuberculosis. Am. J. Vet. Res. 63:12071211.

Whittington R.J., Fell S., Walker D., McAllister S., Marsh I., Sergeant E., Taragel C.A., Marshall D.J. \& Links I.J. 2000. Use of pooled fecal culture for sensitivity and economic detection of Mycobacterium avium subsp. paratuberculosis infection in flocks of sheep. J. Clin. Microbiol. 38:2550-2556.

Whittington R.J., Marsh I., Choy E. \& Cousins D. 1998. Polymorphisms in IS1311, an insertion sequence common to Mycobacterium avium and Mycobacterium avium subsp. paratuberculosis, can be used to distinguish between and within these species. Mol. Cell Probes 12:349-358. 